Pesq. Vet. Bras. 28(1):15-18, janeiro 2008

\title{
Toxoplasma gondii: estudo soro-epidemiológico de suínos da região Sudoeste do Estado do Paraná ${ }^{1}$
}

\author{
Patricia R. Millar ${ }^{*}$, Heitor Daguer ${ }^{3}$, Regiane T. Vicente ${ }^{4}$, \\ Tatiana da Costa ${ }^{4}$, Leila G. Sobreiro ${ }^{5}$ e Maria Regina R. Amendoeira ${ }^{4}$
}

\begin{abstract}
Millar P.R., Daguer H., Vicente R.T., Costa T., Sobreiro L.G. \& Amendoeira M.R.R. 2008. [Toxoplasma gondii: epidemiological study of pigs from southwestern Paraná, Brazil.] Toxoplasma gondii: estudo soro-epidemiológico de suínos da região Sudoeste do Estado do Paraná. Pesquisa Veterinária Brasileira 28(1):15-18. Programa de Pós-Graduação em Higiene Veterinária e Processamento Tecnológico de Produtos de Origem Animal, Universidade Federal Fluminense, Rua Vital Brazil Filho 64, Santa Rosa, Niterói, RJ 24230-360, Brazil. E-mail: patriciariddell@vm.uff.br

This study evaluated the seroprevalence of toxoplasmosis in pigs bred and slaughtered for human consumption. The frequency of the antibody anti-Toxoplasma gondii was investigated in 408 animals from distinct piggeries of 25 cities in the southwestern region of the state of Paraná, Brazil. Serum samples were examined for IgG antibodies specific for T. gondii through the indirect fluorescent antibody test (IFAT). A frequency of $25.5 \%$ of serum samples tested positive for dilutions equal to or greater than 1:64. Statistically significant were not observed in relation to sex and age of the animals. The highest antibody level observed was 4,096 (3.0\%) and the most frequent was 64 (74\%), suggesting that a chronic infection occurred in the population. The high prevalence of the infection found in the swine herds of this region suggests that these herds can be a source of infection for individuals who typically consume this type of raw or badly cooked meat.
\end{abstract}

INDEX TERMS: Toxoplasma gondii, pigs, seroprevalence.

RESUMO.- Avaliou-se a soroprevalência da toxoplasmose em suínos criados e abatidos para consumo humano, por meio da freqüência de anticorpos da classe IgG antiToxoplasma gondii em 408 animais provenientes de plantéis de 25 municípios da região Sudoeste do Estado do Paraná, Brasil. As amostras de soro foram examina-

\footnotetext{
1 Recebido em 13 de outubro de 2006.

Aceito para publicação em 4 de setembro de 2007.

2 Programa de Pós-Graduação em Higiene Veterinária e Processamento Tecnológico de Produtos de Origem Animal, Faculdade de Veterinária. Universidade Federal Fluminense (UFF), Rua Vital Brazil Filho 64, Santa Rosa, Niterói, RJ 24230-360, Brasil. *Autor para correspondência: patriciariddell@vm.uff.br

${ }^{3}$ Serviço de Inspeção Federal, Ministério da Agricultura, Pecuária e Abastecimento, Rua Felipe Schmidt $755,7^{\circ}$ andar, Centro, Florianópolis, SC 88010-002, Brasil.

${ }^{4}$ Laboratório de Toxoplasmose, Departamento de Protozoologia, Instituto Oswaldo Cruz (FIOCruz), Av. Brasil 4365, Manguinhos, Rio de Janeiro, RJ 21045-900. E-mail: amendoeira@ fiocruz.br

${ }^{5}$ Depto Saúde Coletiva Veterinária e Saúde Pública, Faculdade de Veterinária, UFF, Niterói, RJ.
}

das por meio da reação de imunofluorescência indireta (RIFI). Foi encontrada a freqüência de $25,5 \%$ de soros positivos, com diluições iguais ou superiores a 1:64. Não foram observadas diferenças estatisticamente significativas quanto a sexo e a idade dos animais. O maior título observado foi de $4.096(3,0 \%)$ e o mais freqüente foi 64 (74\%) sugerindo que uma infecção crônica estava ocorrendo na população. A alta prevalência da infecção encontrada nos rebanhos suínos estudados sugere que estes possam servir de fonte de infecção para os consumidores que têm o hábito de consumir carne suína crua ou mal cozida.

TERMOS DE INDEXAÇÃO: Toxoplasma gondii, suínos, soroprevalência.

\section{INTRODUÇÃO}

A toxoplasmose é causada pelo protozoário Toxoplasma gondii, parasita intracelular obrigatório, com morfologia variada múltipla em seu ciclo biológico de acordo com o habitat e estádio evolutivo em que se encontra (Amendo- 
eira et al. 1999). Os únicos hospedeiros definitivos da infecção são os felídeos, sendo que os gatos domésticos possuem papel fundamental na transmissão de $T$. gondii para o homem e outros animais, os hospedeiros intermediários (Dubey et al. 1995).

O homem adquire a infecção por três vias principais: ingestão de cistos teciduais em carne crua ou mal cozida, a ingestão de oocistos esporulados e a via transplacentária (Frenkel 1990). A manifestação dos sinais clínicos da toxoplasmose humana e de outros animais depende principalmente da resposta imune do hospedeiro infectado e da virulência da amostra de T. gondii (Luft et al. 1984). A transmissão congênita é importante, tanto para a saúde pública quanto para a sanidade animal e pode ocorrer quando fêmeas não infectadas contraem o parasita durante a prenhez (Dubey et al. 1994). Nos animais, T. gondii causa sintomas como hipertermia, prostração e anorexia, no entanto, os maiores problemas são de âmbito reprodutivo, tais como aborto, repetição de cio, natimortalidade e natimorbidade (Vidotto et al. 1987).

Segundo Dubey (1995), os suínos adquirem a toxoplasmose pela ingestão de água e ração contaminadas com oocistos presentes nas fezes de felinos, cistos presentes em carnes infectadas ou por via transplacentária. Segundo Fialho \& Araújo (2002), os levantamentos sorológicos da toxoplasmose na espécie suína servem para avaliar, além da ocorrência dessa infecção, o risco a que estão expostos os humanos que ingerem carne crua ou mal cozida desses animais. Devido a este fato, diversos autores têm realizado estudos soro-epidemiológicos em suínos em diferentes regiões do Brasil (Ishizuka 1978, Vidotto et al. 1990, Garcia et al. 1999, Tsutsui et al. 2003). Segundo Dias e Freire (2005) a alta produção e consumo de carne suína, a elevada disseminação e prevalência do T. gondii, associada ao fato de que os cistos não são detectáveis ao abate; torna este alimento, quando ingerido cru ou mal cozido, uma importante via de transmissão da toxoplasmose ao homem.

O objetivo deste trabalho foi avaliar a soroprevalência da toxoplasmose em suínos criados em granjas tecnificadas e abatidos para consumo humano na região Sudoeste do Paraná (PR), frente ao importante papel desse Estado na indústria suinícola brasileira.

\section{MATERIAL E MÉTODOS}

Amostras de sangue foram coletadas de 408 suínos, abatidos em um matadouro sob inspeção sanitária na cidade de Palmas, PR e provenientes de distintos criadores de 25 municípios da região Sudoeste do Estado do Paraná (Quadro 1). A coleta ocorreu de novembro de 2004 a abril de 2005, sem distinção de raça na população estudada. As amostras de sangue foram obtidas no momento da sangria dos animais. Os soros foram separados, identificados e armazenados a $-20^{\circ} \mathrm{C}$ até o momento das análises sorológicas.

A amostragem populacional foi obtida utilizando-se 0 programa Epi-Info Versão 6, com expectativa de prevalência de $30 \%$ da infecção por Toxoplasma gondii, obtendo-se, de forma aleatória, uma amostra epidemiologicamente significativa.
Quadro 1. Distribuição dos suínos abatidos na cidade de Palmas no período de novembro de 2004 a abril de 2005, oriundos de 25 diferentes municípios da região Sudoeste do Paraná de acordo com o município de procedência

\begin{tabular}{lc}
\hline \multicolumn{1}{c}{ Município } & $\begin{array}{c}\text { Número de animais } \\
\%(\mathrm{n})\end{array}$ \\
\hline Bom Sucesso do Sul & $5,4(22)$ \\
Chopinzinho & $2,9(12)$ \\
Clevelândia & $2,9(12)$ \\
Coronel Domingues Soares & $2,2(9)$ \\
Coronel Vívida & $5,4(22)$ \\
Cruzeiro do Iguaçu & $5.1(21)$ \\
Dois Vizinhos & $2,7(11)$ \\
Enéas Marques & $4,6(19)$ \\
Flor da Serra & $4,4(18)$ \\
Francisco Beltrão & $7,6(31)$ \\
Itapejara do Oeste & $2,2(9)$ \\
Mariópolis & $3,2(13)$ \\
Mangueirinha & $3,7(15)$ \\
Marmeleiro & $7,6(31)$ \\
Nova Esperança do Sudoeste & $3,2(13)$ \\
Pato Branco & $8,6(35)$ \\
Pranchita & $2,2(9)$ \\
Realeza & $3,7(15)$ \\
Renascença & $3,4(13)$ \\
Salto do Lontra & $2,9(12)$ \\
Santo Antônio do Sudoeste & $2,0(8)$ \\
São João & $3,2(13)$ \\
São Jorge D’Oeste & $5,1(21)$ \\
Verê & $2,9(12)$ \\
Vitorino & $2,9(12)$ \\
Total & $100(408)$ \\
&
\end{tabular}

As análises sorológicas foram realizadas no Laboratório de Toxoplasmose, Instituto Oswaldo Cruz, Rio de Janeiro, entre novembro de 2005 e fevereiro de 2006. Os soros foram examinados para detecção de anticorpos da classe IgG, específicos para $T$. gondii, pela reação de imunofluorescência indireta (RIFI), conforme técnica descrita por Camargo (1964), utilizando-se soro hiperimune anti- T. gondii da classe IgG, obtido no comércio, produzido a partir de inoculações em coelhos, conjugado ao isotiocianato de fluoresceína. Em todas as reações, foram incluídos soros padrões, positivo e negativo, previamente conhecidos.

$\mathrm{O}$ antígeno utilizado foi obtido de exsudato peritonial de camundongos Swiss Webster (Mus musculus), infectados com taquizoítas da cepa $\mathrm{RH}$ de $T$. gondii. Os soros dos suínos foram testados em diluições seqüenciais na base quatro até 1:4096, sendo considerados positivos os títulos maiores ou iguais a 64 .

Os resultados foram submetidos à análise estatística, que para tal se utilizou o teste de Qui-Quadrado $\left(\chi^{2}\right)$ adotando $a=5 \%$.

\section{RESULTADOS E DISCUSSÃO}

A freqüência de anticorpos anti-Toxoplasma gondii obtida nesta pesquisa foi de 25,5\%. Este percentual, embora alto, não difere das médias que vêm sendo relatada, para suínos, em várias regiões do Brasil: 22,5\% (Correa et al. 1978) e 29,72\% (Barci et al. 1998) em São Paulo; 37,84\% (Vidotto et al. 1990) e 24\% (Garcia et al. 1999) no Paraná; e 33,75\% no Rio Grande do Sul (Fialho \& Araújo 2003). Por outro lado, alguns autores têm observado soropreva- 


\begin{tabular}{|c|c|c|c|c|}
\hline \multirow{2}{*}{$\begin{array}{l}\text { Sexo/ } \\
\text { Idade }^{a}\end{array}$} & \multirow[t]{2}{*}{ RIFI } & \multicolumn{2}{|c|}{ Soros analisados } & \multirow{2}{*}{$\begin{array}{c}\text { Análise } \\
\text { estatística }\end{array}$} \\
\hline & & Reagentes & Não-reag & \\
\hline M & $44(24,0 \%)$ & $139(76,0 \%)$ & $183(44,9 \%)$ & $=0,034$ \\
\hline $\mathrm{F}$ & $60(26$ & 165 (73,3\%) & $225(55,1 \%)$ & $p=0,05$ \\
\hline Total & $104(25,5 \%)$ & $304(74,5 \%)$ & 408 & \\
\hline $\mathrm{T}$ & $75(23,3 \%)$ & $247(76,7 \%)$ & $322(78,9 \%)$ & $X 2=3,76$ \\
\hline A & 29 & 66,3 & $86(21,1 \%$ & $\mathrm{p}-\mathrm{U}, \mathrm{c}$ \\
\hline Total & $104(25,5 \%)$ & $304(74,5 \%)$ & 408 & \\
\hline
\end{tabular}

$\overline{\mathrm{a}} \mathrm{M}=$ macho, $\mathrm{F}$ = fêmea, $\mathrm{T}$ = suínos terminados, $\mathrm{A}$ = suínos adultos.

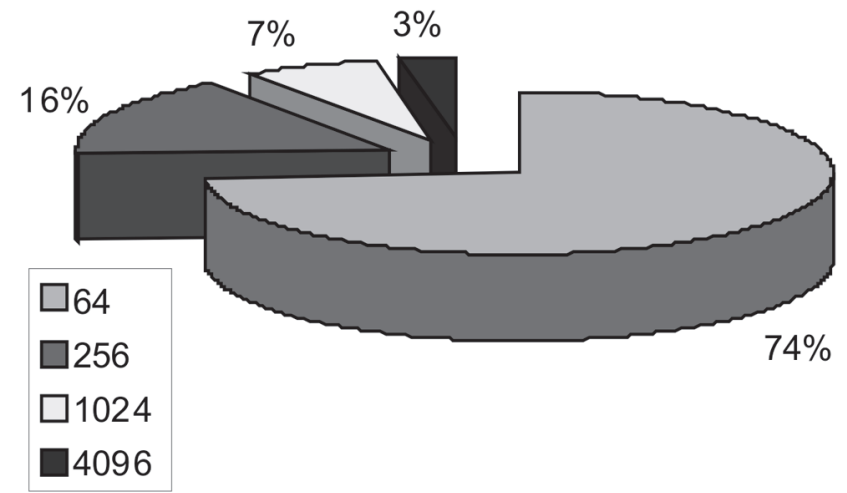

Fig.1. Percentual dos títulos de anticorpos IgG anti-Toxoplasma gondii observados nos suínos soro-reagentes na Reação de Imunofluorescência Indireta.

lências bem mais baixas: 1,11\% no Rio de Janeiro (Souza 1995) e 15,35\% no Paraná (Tsutsui et al. 2003).

Diferenças estatisticamente significativas não foram observadas no que diz respeito ao sexo e a idade dos animais (Quadro 2); o que difere dos resultado observado por Tsutsui et al. (2003), que puderam comprovar estatisticamente o aumento da soroprevalência de acordo com o aumento da faixa etária dos suínos.

Como pode ser visto na Figura 1, o maior título observado no presente estudo foi de $1: 4096(3,0 \%)$ e o mais freqüente foi 1:64 (74\%). Garcia et al. (1999) estudando 267 suínos também oriundos do Estado do Paraná obtiveram como maior título à diluição de 1:8192 $(1,6 \%)$ e o mais freqüente de 1:64 $(56,3 \%)$ sugerindo que uma infecção crônica estava ocorrendo naquela população, assim como na presente pesquisa.

A importância de suínos como fonte de infecção para T. gondii já foi relatada por diversos autores. Dubey (1998) isolou T. gondii em 14 de 16 suínos positivos para toxoplasmose. O parasita foi isolado de coração, língua, cérebro e diafragma dos animais. $\mathrm{O}$ autor relata ainda a possibilidade de outros tecidos estarem infectados. Dias et al. (2005), com o objetivo de verificar a presença de cistos de $T$. gondii em 149 lingüiças de origem suína tipo frescal, encontraram $13(8,72 \%)$ amostras positivas, infe- rindo a importância deste produto cárneo na cadeia epidemiológica da toxoplasmose. Mais recentemente FrazãoTeixeira et al. (2006) estudando encéfalos de suínos comercializados para consumo humano no município de Campos dos Goytacazes, Estado do Rio de Janeiro, verificaram o percentual de $50 \%$ de positividade para presença do parasita. Levando-se em consideração que muitas vezes os cérebros, juntamente com a musculatura são utilizados na preparação de embutidos (lingüiça e chouriço), existe um risco real de infecção pelo consumo de vísceras cruas desses animais (Suarez-Aranda et al. 2000).

Outro fator a ser considerado é a importância dos suínos como fonte de infecção para magarefes e outros funcionários de frigoríficos que lidam diretamente com esses animais e suas carcaça. Tal afirmação é corroborada pelo encontro de alta freqüência de soro-reagentes entre funcionários do frigorífico onde foram coletadas as amostras de suínos para o presente estudo (Millar et al. 2007). Naquela Indústria 156 trabalhadores foram submetidos à pesquisa de anticorpos anti-Toxoplasma gondii por meio da reação de imunofluorescência indireta, obtendo um percentual de $58,6 \%$ de soro-reagentes (Millar et al. 2007), resultando semelhante, $59,5 \%$ de positividade, foi encontrado por Dias et al. (2005) com a mesma técnica sorológica, em outra cidade do mesmo estado em indivíduos que trabalhavam em outras atividades com a mesma espécie animal. Os dados obtidos reforçam a necessidade de um manejo de criação adequado, visando minimizar o risco de infecção de suínos por T. gondii.

Agradecimentos.- À Profa. Dra. Roberta L. Freire, Universidade Estadual de Londrina (UEL), pelos soros-controle positivos e negativos e, à CAPES, pelo financiamento do estudo.

\section{REFERÊNCIAS}

Amendoeira M.R.R., Costa T. \& Spalding S.M. 1999. Toxoplasma gondii Nicolle et Manceaux, 1909 (Apicomplexa: Sarcocystidae) e a toxoplasmose. Revta Souza Marques 1(1):15-29.

Barci L.A.G. 1998. Freqüência de anticorpos anti-Toxoplasma gondii em plantéis de suínos reprodutores no Estado de São Paulo, Brasil. Arqs Inst. Biológico, São Paulo, 65(1):111-113.

Camargo M.E. 1964. Improved technique of indirect immunofluorescence for serological diagnosis of toxoplasmosis. Revta Inst. Med. Trop. São Paulo 6:117-118.

Correa F.M.A., Salata E. \& Oliveira M.R. 1978. Toxoplasma gondii: diagnóstico pela prova de imunofluorescência indireta em suínos do estado de São Paulo, Brasil. Arqs Inst. Biológico, São Paulo, 45(4):209212.

Dias R.A.F. \& Freire R.L. 2005. Surtos de toxoplasmose em seres humanos e animais. Semina, Ciênc. Agrárias, Curitiba, 26(2):239-247.

Dias R.A.F., Navarro I.T., Ruffolo B.B., Bugni F.M., Castro M.V. \& Freire R.L. 2005. Toxoplasma gondii in fresh pork sausage and seroprevalence in butchers from factories in Londrina, Paraná State, Brazil. Revta Inst. Med. Trop. São Paulo 47(4):185-189.

Dubey J.P., Baker D.G., Davis S.W., Urban J.F.Jr \& Shen S.K. 1994. Persistence of immunity to toxoplasmosis in pigs vaccinated with a non-persistent strain of Toxoplasma gondii. Am. J. Vet. Res. 55(7):982987.

Dubey J.P., Weigel R.M., Seigel A.M., Kitron U.D., Mannelli A., Mitchell 
M.A., Mateus-Pinilla N.E., Thulliez P., Shen S.K., Kwok O.C.H. \& Todd K.S. 1995. Risk factors for transmission of Toxoplasma gondii on swine farms in Illinois. J. Parasitol. 81(5):736-741.

Fialho C.G. \& Araújo F.A.P. 2002. Comparação entre os testes de imunofluorescência indireta e hemaglutinação indireta para detecção de anticorpos anti-Toxoplasma gondii em soros de suínos. Acta Sci. Vet. 30(3):185-189.

Fialho C.G. \& Araújo F.A.P. 2003. Detecção de anticorpos para Toxoplasma gondii em soro de suínos criados e abatidos em frigoríficos da região da Grande Porto Alegre-RS, Brasil. Ciencia Rural, Santa Maria, 33(5):893-897.

Frazão-Teixeira E., Oliveira F.C.R., Pelissari-Sant'ana V. \& Lopes C.W.G. 2006. Toxoplasma gondii em encéfalos de suínos comercializados no município de Campos dos Goytacazes, estado do Rio de Janeiro, Brasil. Revta Bras. Parasitol. Vet. 15(1):33-36.

Garcia J.L., Navarro I.T., Ogawa L. \& Oliveira R.C. 1999. Soroprevalência de Toxoplasma gondii em suínos, bovinos, ovinos e eqüinos e sua correlação com humanos, felinos e caninos, oriundos de propriedades rurais do norte do Paraná, Brasil. Ciência Rural, Santa Maria, 29(1):91-97.

Ishizuka M.M. 1978. Avaliação da freqüência de reagentes ao Toxoplasma gondii, pela prova de imunofluorescência indireta, em suínos de matadouro do município de São Paulo. Revta Fac. Med. Vet. Zootec. USP 15(2):151-154.

Luft B.J. \& Remington J.S. 1992. Toxopasmic encephalitis in AIDS. Clin. Infect. Dis. 15(2):211-222.
Millar P.R., Daguer H., Trigueiro R.V., Costa T., Carli A.L., Sobreiro L.G. \& Amendoeira M.R.R. 2007. Soroprevalência de anticorpos antiToxoplasma gondii em trabalhadores de um matadouro de suínos e em indivíduos com outras atividades na cidade de Palmas, Paraná, Brasil. Ciência Rural, Santa Maria, 37(1):292-295.

Smith H.J. 1991. Seroprevalence of anti-toxoplasma IgG in Canadian swine. Can. J. Vet. Res. 55:380-381.

Souza W.J.S. 1995. Epidemiologia da toxoplasmose: avaliação sorológica de suínos e trabalhadores em abatedouros na mesorregião do Grande Rio de Janeiro. Itaguaí, 1995. Tese de Doutorado em Parasitologia Veterinária, Universidade Federal Rural do Rio de Janeiro, Itaguaí, RJ. 143p.

Suaréz-Aranda F., Galisteo A.J., Hiramoto R.M., Cardoso R.P., Meireles L.R., Miguel O. \& Andrade H.F.Jr 2000. The prevalence and avidity of Toxoplasma gondii IgG antibodies in pigs from Brazil and Peru. Vet. Parasitol. 91(1-2):23-32.

Tsutsui V.S., Navarro I.T., Freire R.L., Freitas J.C., Prudencio L.B., Delbem A.C.B. \& Marana E.R.M. 2003. Soroepidemiologia e fatores associados à transmissão do Toxoplasma gondii em suínos no norte do Paraná. Arch. Vet. Sci., Curitiba, 8(2):27-34.

Vidotto O., Costa A.J., Balarin M.R.S. \& Rocha M.A. 1987. Toxoplasmose experimental em porcas gestantes. I. Observações Clínicas e Hematológicas. Arq. Bras. Med. Vet. Zootec. 39(4):623-639.

Vidotto O., Navarro I.T., Giraldi N., Mitsuka R. \& Freire R.L. 1990. Estudos epidemiológicos da toxoplasmose em suínos da região de Londrina, PR. Semina, Curitiba, 11(1):53-59. 